\title{
1 Increased subchondral bone thickness in hips with cam-type femoroacetabular
}

\section{2 impingement}

3

4 Martina Bieri ${ }^{1}$, Martin Beck ${ }^{2 *}$, Andreas Limacher ${ }^{3}$, Michael C Wyatt ${ }^{2}$, Michael Leunig ${ }^{4}$, Peter Jüni ${ }^{5}$ and 5 Stephan Reichenbach ${ }^{5,6}$

6

$7 \quad{ }^{1}$ Clinic of Paediatrics, Luzerner Kantonsspital Luzern, Switzerland

$8 \quad{ }^{2}$ Clinic for Orthopaedic and Trauma Surgery, Luzerner Kantonsspital, Luzern, Switzerland

$9{ }^{3}$ Clinical Trial Unit Bern, Department of Clinical Research, and Institute of Social and Preventive Medicine (ISPM), University of Bern, Switzerland

${ }^{4}$ Schulthess Clinic, Department of Orthopaedics, Zürich, Switzerland

${ }^{5}$ Institute of Primary Health Care (BIHAM), University of Bern, Switzerland

${ }^{6}$ Department of Rheumatology, Immunology and Allergology, University Hospital and University of Bern, Switzerland

*Corresponding author at: Martin Beck, Clinic for Orthopaedic and Trauma Surgery, Luzerner Kantonsspital Spitalstrasse 4, 6004 Luzern, Switzerland. Email: martin.beck@luks.ch

Keywords: Cam, MRI, subchondral bone changes 
Table 1: Comparison of attenders of MRI examination with non-attenders and non-invited individuals.

Table 2: Comparison of measurements in hips with and without cam-type deformity.

Table 3: Comparison of shapes of sclerosis in hips with and without cam-type deformity.

Table 4: Intra-rater ICC for the different parameters.

Figure 1: Segment with subchondral sclerosis/length (B) represents the border of the osseous acetabulum without labrum and (C) the end of the subchondral sclerosis along the circle with Radius ra

Figure 2: Thickness of the subchondral sclerosis

Figure 3: Shape of subchondral sclerosis.

Figure 4: Study flow chart. Adapted from Reichenbach et al. ${ }^{10}$ 
Objectives: Increased thickness of subchondral acetabular bone with associated articular cartilage thinning in hips with femoroacetabular (FAl) cam impingement has been observed on magnetic resonance imaging (MRI). Dynamic attrition by the cam deformity moving into the acetabulum may potentiate trans-articular shear stresses thus causing these subchondral bone changes. We aimed to quantify the hypertrophic changes of subchondral acetabular bone in patients with cam-type FAl.

Methods: MRI studies were performed on an asymptomatic population of young Swiss army recruits. Subjects underwent clinical examination and completed questionnaires before undergoing an MRI of the hip. Cam deformities were graded and the dimensions of the acetabular subchondral bone quantified. Univariate linear regression was used to determine the association between the presence of cam deformities and the degree of subchondral acetabular sclerosis.

Results: There was a strong association between cam deformities and the thickness, area and shape of subchondral sclerosis. The main increase in hypertrophy was observed in the antero-superior acetabulum where impingement typically occurs. The subchondral sclerosis was $0.66 \mathrm{~mm}$ thicker in cam-type deformities than in hips without cam-type deformities $(95 \% \mathrm{Cl}, 0.38-0.93, \mathrm{p}$ value $<$ $0.001)$.

Conclusions: Mechanical stress in the antero-superior acetabular area is elevated in hips with a camtype deformity. The study supports the concept that cam-type deformity induced stress leads to hypertrophy of subchondral acetabular bone in the area of impingement. This is collocated with the clinically observed cartilage damage caused by the cam mechanism. 


\section{INTRODUCTION}

Osteoarthritis $(\mathrm{OA})$ of the hip is a degenerative joint disease involving the whole joint, but it was defined primarily as a pathological process with focal and progressive hyaline articular cartilage loss. The underlying cancellous bone becomes sclerotic and thickened. Concomitant development of osteophytes is possible and soft-tissue structures in and around the joint are typically affected. ${ }^{1}$ The aetiology of $\mathrm{OA}$ is multifactorial and several components such as age, gender, genetic factors and biomechanical factors have been shown to contribute to its development and progression. ${ }^{2,3} \mathrm{OA}$ is considered secondary if aetiologic factors can be determined, and idiopathic if they cannot. ${ }^{4}$ Minor developmental deformities of the acetabulum and/or proximal femur can cause a pathological abutment of the femoral neck against the acetabular rim. These mechanisms have been termed femoroacetabular impingement (FAI). In several recent studies FAI was shown to cause hip OA, and many cases of hip OA that previously were classified as idiopathic can now be classified as secondary to FAl. ${ }^{5,62}$ different types of FAl, called "cam-"and "pincer-" impingement, can be distinguished. Cam-FAl is caused by an aspherical extension of the femoral head-neck junction. Pincer-FAl is secondary to local or general over-coverage of the acetabulum. The 2 types of FAl are often combined. ${ }^{7}$ The cam-FAl is more important because it leads to early and more extensive acetabular cartilage damage, ${ }^{7}$ and chondral damage of the acetabulum is generally observed at surgery even when the articular cartilage of the femur is unchanged. ${ }^{8,9}$ Cam deformities are frequent. In a recent magnetic resonance imaging (MRI) study a cam deformity was present in a quarter of young asymptomatic patients. ${ }^{10}$

In clinical practice sclerosis of the subchondral bone at the acetabular rim in the presence of cam-FAI is observed, occasionally combined with a decrease in articular cartilage thickness. Recently, a study explored bone mineral density around the acetabulum and showed increased subchondral bone mineral density in a small group of patients with cam impingement. ${ }^{11}$ We hypothesised that the thickness of the subchondral acetabular bone correlates with the size of the cam deformity. 


\section{MATERIALS AND METHODS}

244 asymptomatic Sumiswald Swiss army recruits underwent hip MRI. The presence of a cam deformity and relationship to the thickness, area and shape of the subchondral bone was measured. The Sumiswald Cohort is a population-based cohort of consecutive young males being conscripted into the Swiss army at a single recruitment centre in Sumiswald, Switzerland. ${ }^{10}$ Data from the Sumiswald Cohort have already been previously published. ${ }^{12,13}$ The study was approved by the Research Ethics Committee of the Canton of Bern. All of the participants provided informed consent prior to data collection.

\section{Magnetic resonance imaging (MRI) and cam-deformity grading}

MRI studies used a flexible surface coil with high spatial resolution protocol, and were performed with a 1.5 Tesla high-field system (Magnetom Avanto, Siemens, Erlangen, Germany). Scans were performed with subjects supine with the hip joints in a neutral rotation. Radial proton-densityweighted sequences were acquired with all slices oriented parallel to the femoral neck axis, which was used as the axis of rotation. Sequences were performed using a sagittal oblique localiser, which was marked on the proton density-weighted coronal sequence and which ran parallel to the sagittal oblique course of the acetabulum.13 For the turbo-spin-echo (TSE) pulse sequence, images were obtained with a time to recovery of $2000 \mathrm{msec}$, time to echo (TE) of $15 \mathrm{msec}$, field of view of $260 \times$ $260 \mathrm{~mm}$, matrix of $266 \times 512$ and slice thickness of $4 \mathrm{~mm}$. The acquisition time to complete a set of 16 slices was $4 \mathrm{~min} 43 \mathrm{sec}$. The resulting voxel size was $0.98 \times 0.51 \times 4 \mathrm{~mm}$. In addition, we used a transverse T1- weighted sequence (field of view (FOV) $200 \times 200 \mathrm{~mm}$, slice thickness $4 \mathrm{~mm}$, repetition time (TR) $650 \mathrm{~ms}$, time of echo (TE) $20 \mathrm{~ms}$ ); transverse fast low-angle shot sequence (FOV $120 \times 120 \mathrm{~mm}$, section thickness $2 \mathrm{~mm}$, TR $650 \mathrm{~ms}$, TE $20 \mathrm{~ms}$, flip angle $90^{\circ}$ ); sagittal trueFISP 3D sequence (FOV $130 \times 130 \mathrm{~mm}$, section thickness $1.5 \mathrm{~mm}$, TR $8.87 \mathrm{~ms}$, TE $3.23 \mathrm{~ms}$, flip angle $28^{\circ}$ ); sagittal inversion recovery sequence (FOV $180 \times 180 \mathrm{~mm}$, section thickness $3 \mathrm{~mm}$, TR $4800 \mathrm{~ms}$, TE 32 ms, time of inversion $160 \mathrm{~ms}$ ); and coronal true FISP 3D sequence (FOV $180 \times 180 \mathrm{~mm}$, section 
thickness $1.5 \mathrm{~mm}$, TR $8.16 \mathrm{~ms}$, TE $2.89 \mathrm{~ms}$, flip angle $28^{\circ}$ ). Neither intraarticular nor intravenous contrast was injected for ethical reasons.

To determine the presence of cam-type deformities, the maximal offset at the head-neck junction on the radial sequences was graded using a semi-quantitative scoring system, in which grades ranged from 0 to 3: $0=$ normal, no evidence of cam deformity on any sequence; $1=$ possible deformity with cortical irregularity and a small decrease of anterior head-neck offset; 2 = definite cam deformity with an established decrease of anterior headneck offset (cam deformity of less than $10 \mathrm{~mm}$ ); 3 = severe deformity with a large decrease in the anterior head-neck offset (cam-type deformity of more than $10 \mathrm{~mm}) .{ }^{10}$ This grading was already used in previous studies on this study cohort. ${ }^{12,13}$

\section{Quantification of subchondral sclerosis}

Previous work has shown the good accuracy of measurements of bone structures on MRI. ${ }^{14-17}$ We used a clock face system to specify radial planes. The 6 o'clock position was taken as the plane in the middle of the tear drop figure and 12 o'clock opposite of the hip centre. 8 radial planes of the anterior-superior area were analysed, starting with the plane directly posterior to that at the 12 o'clock position.

As a starting point for all the measurements, a circle was drawn from the centre of the femoral head The circle was centred using the subchondral black line of the femoral head and enlarged until it reached the subchondral sclerosis of the acetabulum. This circle ( $\mathrm{ra}$ ) was recorded and used as base for further measurements. The circle was enlarged until it reached the peripheral border of the subchondral sclerosis and the radius ( $r b$ ) was measured. If subchondral bone extended into the cartilage, the circle was placed at the central border of the sclerosis and the radius ( $\mathrm{rc}$ ) was recorded. 
measured (Figure 1). The thickness of the sclerosis was calculated based on the difference between the circle with radius ra and the radius rb of the circle extending to the end of the sclerosis within the bone and/or (depending on which possibility was present) the radius $\mathrm{rc}$ of the circle touching the beginning of the sclerosis within the cartilage (Figure $2(A)$ and $(B)$ ). The difference between the circles' radii defined the thickness of the sclerosis within the bone and the thickness of the decreased cartilage. The sum of these 2 values defined the entire thickness of the sclerosis. Beside the length and the thickness of the sclerosis, also its area was measured. Finally, the shape of the sclerosis was qualitatively evaluated as shown in Figure 3 (Figure 3(A-G)).

\section{Statistical analysis}

Measurements of subchondral sclerosis were assessed on each plane and were aggregated taking the maximal value per participant. Univariate linear regression was used to determine associations between the presence of cam-type deformities and different measurements of sclerosis, with results expressed as differences, including a 95\% confidence interval $(\mathrm{Cl})$ and a corresponding $\mathrm{p}$ value.

A mixed-effects multinomial logistic model accounting for the correlation of data within subjects was used to determine associations between cam deformity and dimensions of subchondral sclerosis as measured in each plane. Associations are expressed as odds ratios, including a $95 \% \mathrm{Cl}$ and a corresponding $p$ value. The category 'no visible shape of sclerosis was taken as reference. All analyses were performed using Stata 14 (Stata Corporation, College Station, Texas). Since this was not a diagnostic study only intra-rater variability was examined using the Pearson correlation coefficient.

\section{RESULTS}

All participants were recruited between March and July 2005. A flow chart of subject progression through the study is shown in Figure 4. The mean age of participants undergoing MRI was 19.9 years 
(standard deviation $[S D] \pm 0.7)$, while the mean body mass index was $23.1 \mathrm{~kg} / \mathrm{m} 2(\mathrm{SD} \pm 3.7)$. In 113 cases (46\%) the left hip was imaged.

67 of the 244 hips had a definite cam deformity with an overall adjusted prevalence of $24 \%(95 \% \mathrm{Cl}$ 19-30\%). ${ }^{14}$ The mean \pm SD alpha angle for grade 0 deformities was $44.8^{\circ} \pm 8.4^{\circ}$, for grade 1 deformities $48.4^{\circ} \pm 10.1^{\circ}$, for grade 2 deformities $57.7^{\circ} \pm 12.7^{\circ}$, and grade 3 deformities $76.4^{\circ} \pm 9.7^{\circ}$ ( $p$ value $=0.001$ for trend). Table 1 shows how the MRI features of the study subjects compared to non-attenders and controls.

Hips with a cam deformity showed increased thickness and length of the subchondral sclerosis. The BC-angle, representing sclerosis' angular length, was $1.51^{\circ}$ higher in subjects with compared to subjects without a cam-type deformity $(95 \% \mathrm{Cl},-1.03-4.06, \mathrm{p}=0.242)$. The mean thickness of sclerosis within bone was $3.25 \mathrm{~mm}(95 \% \mathrm{Cl}, 3.02-3.48)$ in the acetabulae of hips with a cam-type deformity and $2.59 \mathrm{~mm}(95 \% \mathrm{Cl}, 2.45-2.73)$ in those without (difference $0.66,95 \% \mathrm{Cl}, 0.38-0.93, \mathrm{p}$ $<0.001)$. In hips without a cam deformity the mean area of sclerosis was $21.69 \mathrm{~mm} 2(95 \% \mathrm{Cl}, 20.02-$ 23.36), while in hips with a cam-type deformity the area increased by $5.05 \mathrm{~mm} 2(95 \% \mathrm{Cl}, 1.86-8.24$, $\mathrm{p}=0.002)$ to a mean of $26.74 \mathrm{~mm} 2(95 \% \mathrm{Cl}, 24.02-29.45)$.

In cases where the sclerosis involved the cartilage, hips without cam-type impingement demonstrated cartilaginous penetration that was $0.13 \mathrm{~mm}$ deeper $(95 \% \mathrm{Cl},-0.02-0.27, \mathrm{p}=0.081)$ (Table 2). 4 shapes were significantly associated with cam-type deformity (Table 3). The odds of a triangular shape instead of no visible sclerosis on a given plane were 3.56 times higher $(95 \% \mathrm{Cl}, 2.17-5.82, \mathrm{p}<$ $0.001)$ if a cam-type deformity was present. The odds of a hook-shaped sclerosis were $2.73(95 \% \mathrm{Cl}$, 1.26-5.92, $\mathrm{p}=0.011)$ times higher, while the odds of a linear shape were $2.25(95 \% \mathrm{Cl}, 1.29-3.90, \mathrm{p}$ $=0.004)$ higher and the odds of an irregular-shape were $3.28(95 \% \mathrm{Cl}, 2.01-5.35, \mathrm{p}<0.001)$ higher in

177 subjects with cam-type deformity. excellent (Table 4). 


\section{DISCUSSION}

This cross-sectional study of 244 asymptomatic Swiss Army recruits shows a strong correlation between subchondral bone hypertrophy at the acetabular rim and the presence of cam-type deformity. The antero-superior area was particularly affected and is where cartilaginous damage in cam impingement is generally found in contrast to the circumferential damage in pincer impingement. ${ }^{7,18}$

The dimensions of subchondral sclerosis differed between hips depending on the presence of cam deformity. The thickness of sclerosis was significantly greater in hips with cam deformities (difference $0.66 \mathrm{~mm}, \mathrm{p}$ value $<0.001$ ). If the hypertrophy involved the cartilage, there was a small insignificant difference between hips with and those without cam-type deformities, with hips with cam-type deformity showing less hypertrophy. The mean area of sclerosis was also significantly greater in the presence of cam-type deformity $(p$ value $=0.002)$. Triangular, irregular, linear and hook-shaped sclerosis was significantly associated with a cam-type deformity.

The mean thickness of subchondral sclerosis in hips without cam-type deformity was $3.03 \mathrm{~mm}$ (95\% $\mathrm{Cl}, 2.88-3.19)$ and represents the normal thickness of subchondral bone. This is the 1 st study to standardise values for subchondral bone in a young male population. This is important in future research evaluating MR images. Our study is also the 1st to define the impact of cam impingement on the thickness, volume and shape of subchondral sclerosis of the antero-superior acetabulum. A computed tomography (CT) study on a small group of patients by Speirs et al. ${ }^{11}$ showed that subjects with cam FAl have an increased bone mineral density in the antero- superior acetabulum. This might be explained by the increased load transfer caused by the cam FAl and is corroborated by finite element studies. ${ }^{19,20}$

In hip dysplasia the reduced contact area and hence static concentration of stresses at the acetabular rim leads to increased sclerosis of the subchondral bone. ${ }^{21}$ In contrast, cam impingement causes high shear stresses within the cartilage and adjoining subchondral bone via a dynamic, 
attritional mechanism. ${ }^{19,20}$ Chegini et al. ${ }^{19}$ showed that stresses within the labrum and acetabular cartilage depend highly on the geometry of the bony anatomy.

When FAI was purported to cause OA in young subjects, the primary source leading to the development of OA was believed to be shear forces at the tidemark between cartilage and subchondral bone, which then led to maceration and eventually to flap formation with subsequent destruction of the cartilage. ${ }^{7}$ The location of the cartilage damage in cam FAl collocates with the location of subchondral hypertrophy in this study. 7,18 debated: Radin et al. ${ }^{22}$ observed a correlation between OA and thickening of subchondral bone inferring that loss of elasticity leads to elevation of cartilaginous stress and subsequently to degeneration. This hypothesis has been supported by various studies. ${ }^{23-25}$ Conversely Burr et al. ${ }^{26}$ suggested that mechanical overload initiates micro damage of subchondral bone which triggers a biological response at the tidemark by a reactivation of the secondary centre of ossification and hence enchondral ossification. This leads to thickening of the mineralised tissues and thinning of the overlying hyaline articular cartilage. As described previously, this hypertrophy can be considered to be a reaction to stress and is an effect rather than a cause of cartilage degeneration. Because the concept of FAl explains the direct mechanical damage of the joint cartilage by the cam deformity, it is less likely that cartilage damage occurs secondarily to stiffening of the hypertrophic subchondral bone. However, the subchondral hypertrophy induced by the stresses caused by the cam mechanism probably adds to the cartilage stress and damage secondarily as shown by Wei et al. ${ }^{27}$ It remains unclear why hypertrophy in hips with cam deformities extends less into the cartilage than in those without. We would expect more thickening in cam-type deformities as the stress is augmented. However, morphologic development of articular cartilage is influenced by biologic adaption to functional demands. ${ }^{28}$ It was shown that advancement of the subchondral ossification front towards the joint surface is inhibited by intermittent hydrostatic pressure. ${ }^{29}$ This may explain 
why increased stress inhibits advancement of the tidemark and ossification of the uncalcified cartilage layer.

Our study can be criticised as only young males were examined. The study group is a reasonable size but is a very narrow proportion of the population and is only young males with a normal BMI. Although these recruits are conscripted they still represent a narrow cohort. A further limitation is that while the shape of the femur was assessed and classified, that of the acetabulum was not. The definitions of acetabular cover and depth are based on standard radiographs and it is very difficult to assess the shape of the acetabulum on MRI. In acetabular over-coverage the cam mechanism has the same mechanical effect and would not influence our findings. Because of the decreased weightbearing area in acetabular dysplasia, hypertrophy of the subchondral bone can be observed. ${ }^{21}$ However, dysplastic hips rarely present with a cam deformity and would have been classified into the normal group, leading to an overestimation of subchondral sclerosis in this group. Only $57 \%$ of our cohort consented for MRI. However, the analysis of the characteristics of participants and nonparticipants did not show significant differences (Table 1). Compared to studies with older individuals, the young age of participants makes it less likely that the osseous alterations are caused by factors such as age, or osteoarthrosis. Nevertheless, long-term studies and examination of children are required as it is still impossible to distinguish between developmental disorders and alterations purely resulting from cam-type deformities.

A last limitation of this study is the difficulty in clearly defining and demarcating the measured hypertrophy. Interfering factors such as published recently, ${ }^{12}$ normal developmental differences and the angular intersection through the acetabular and supraacteabular fossa, made a clear differentiation of the hypertrophy sometimes difficult. However, the accuracy, reliability, inter-rater and intra-rater reliability of subchondral bone and cartilage thickness measurement from MRI were shown to be excellent. ${ }^{14-17}$ 
255 The author(s) declared the following potential conflicts of interest with respect to the research,

256 authorship, and/or publication of this article: PJ: serves as unpaid member of the steering group of

257 trials funded by Astra Zeneca, Biotronik, Biosensors, St. Jude Medical, and The Medicines Company.

258 All other authors declare that there is no conflict of interest

259

260 FUNDING

261 The author(s) disclosed receipt of the following financial support for the research, authorship and/or

262 publication of this article: The study was supported by the Swiss National Science Foundation

263 (National Research Program 53 on Musculoskeletal Health grant 405340-104778) 


\section{REFERENCES}

1. Kumar V, Abbas AK, Fausto N, et al. Joint, osteoarthritis. In: Schmitt W (ed.) Robbins basic pathology. Philadelphia: Saunders, 2007, pp.818-820.

2. Harris WH. Etiology of osteoarthritis of the hip. Clin Orthop Relat Res 1986; 213: 20-33.

3. Busija L, Bridgett L, Williams SR, et al. Osteoarthritis. Best Pract Res Clin Rheumatol 2010; 24: 757-768.

4. Flores R. Definition and classification of osteoarthritis. Oxford: Oxford University Press, 2003.

5. Ganz R, Parvizi J, Beck M, et al. Femoroacetabular impingement: a cause for osteoarthritis of the hip. Clin Orthop Relat Res 2003; 417: 112-120.

6. Ganz R, Leunig M, Leunig-Ganz K, et al. The etiology of osteoarthritis of the hip: an integrated mechanical concept. Clin Orthop Relat Res 2008; 466: 264-272.

7. Beck $M$, Kalhor $M$, Leunig $M$, et al. Hip morphology influences the pattern of damage to the acetabular cartilage: femoroacetabular impingement as a cause of early osteoarthritis of the hip. J Bone Joint Surg Br 2005; 87:1012-1018.

8. Leunig $M$, Beck $M$, Dora $C$, et al. Femoroacetabular impingement: trigger for the development of coxarthrosis. Der Orthopade 2006; 35: 77-84.

9. Beck $M$, Leunig $M$, Parvizi J, et al. Anterior femoroacetabular impingement Part II. Midterm results of surgical treatment. Clin Orthop Relat Res 2004; 418: 67-73.

10. Reichenbach $S$, Juni $P$, Werlen $S$, et al. Prevalence of camtype deformity on hip magnetic resonance imaging in young males: a cross-sectional study. Arthritis Care Res (Hoboken) 2010; 62: 1319-1327.

11. Speirs AD, Beaulé $P E$, Rakhra KS, et al. Increased acetabular subchondral bone density is associated with cam-type femoroacetabular impingement. Osteoarthritis Cartilage 2013; 21 : 551-558.

12. Reichenbach $S$, Leunig $M$, Werlen $S$, et al. Association between cam-type deformities and magnetic resonance imaging-detected structural hip damage: a cross-sectional study in young men. Arthritis Rheum 2011; 63: 4023-4030.

13. Leunig $M$, Jüni $P$, Werlen $S$, et al. Prevalence of cam and pincer-type deformities on hip MRI in an asymptomatic young Swiss female population: a cross-sectional study. Osteoarthritis Cartilage 2013; 21: 544-550.

14. Manske SL, Kontulainen S, Liu D, et al. Accuracy and reliability of MRI to measure human bone geometry. Paper presented at 5th Combined Meeting of the Orthopaedic Research Societies of Canada, USA, Japan and Europe, Banff, Alberta, Canada, October 10-14, 2004.

15. Manske SL, Liu-Ambrose T, de Bakker PM, et al. Femoral neck cortical geometry measured with magnetic resonance imaging is associated with proximal femur strength. Osteoporos Int 2006; 17: 1539-1545.

16. McGibbon CA. Inter-rater and intra-rater reliability of subchondral bone and cartilage thickness measurement from MRI. Magn Reson Imaging 2003; 21: 707-714.

17. Woodhead HJ, Kemp AF, Blimkie CJ, et al. Measurement of midfemoral shaft geometry: repeatability and accuracy using magnetic resonance imaging and dual-energy $\mathrm{X}$-ray absorptiometry. J Bone Miner Res 2001; 16: 2251-2259.

18. Tannast $M$, Goricki D, Beck M, et al. Hip damage occurs at the zone of femoroacetabular impingement. Clin Orthop Relat Res 2008; 466: 273-280. 
19. Chegini S, Beck M and Ferguson SJ. The effects of impingement and dysplasia on stress distributions in the hip joint during sitting and walking: a finite element analysis. J Orthop Res 2009; 27: 195-201.

20. Speirs $A D$, Beaulé $P E$, Ferguson SJ, et al. Stress distribution and consolidation in cartilage constituents is influenced by cyclic loading and osteoarthritic degeneration. J Biomech 2014; 47: 2348-2353.

21. Pauwels F. Biomechanics of the locomotor apparatus: Contributions on the functional anatomy of the locomotor apparatus. New York: Springer-Verlag, 1980.

22. Radin EL, Burr DB, Caterson B, et al. Mechanical determinants of osteoarthrosis. Semin Arthritis Rheum 1991; 21:12-21.

23. Boyce TM, Fyhrie DP, Glotkowski MC, et al. Damage type and strain mode associations in human compact bone bending fatigue. J Orthop Res 1998; 16: 322-329.

24. Brown TD, Radin EL, Martin RB, et al. Finite element studies of some juxtarticular stress changes due to localized subchondral stiffening. J Biomech 1984; 17: 11-24.

25. Radin EL, Parker HG, Pugh JW, et al. Response of joints to impact loading. 3. Relationship between trabecular microfractures and cartilage degeneration. J Biomech 1973; 6:51-57.

26. Burr DB and Radin EL. Microfractures and microcracks in subchondral bone: are they relevant to osteoarthrosis? Rheum Dis Clin North Am 2003; 29: 675-685.

27. Wei HW, Sun SS, Jao SH, et al. The influence of mechanical properties of subchondral plate, femoral head and neck on dynamic stress distribution of the articular cartilage. Med Eng Phys 2005; 27: 295-304.

28. O'Connor KM. Unweighting accelerates tidemark advancement in articular cartilage at the knee joint of rats. J Bone Miner Res 1997; 12: 580-589.

29. Carter DR and Wong M. Modelling cartilage mechanobiology. Philos Trans R Soc Lond B Biol Sci 2003; 358: 1461-1471. 
335 Table 1: Comparison of attenders of MRI examination with non-attenders and non-invited

336 individuals.

337 BMI, body mass index; §WOMAC, Western Ontario and McMaster University Osteoarthritis Index

338 standardised to range from 0 to 10; §§ EuroQol,

339 European Quality of Life standardised to range from 0 to 10; MRI, magnetic resonance imaging.

340 Note: All data are reported as mean \pm standard deviation. \#p values for the comparison between the

3413 groups derived from one-way ANOVA.

342 Adapted from Reichenbach et al. ${ }^{14}$

\begin{tabular}{|c|c|c|c|c|}
\hline & \multicolumn{2}{|l|}{ Invited for MRI } & \multirow{2}{*}{$\frac{\text { Not invited for MRI }}{(n=650)}$} & \multirow[t]{2}{*}{$p$ value } \\
\hline & Attenders $(n=244)$ & Non-attenders $(n=186)$ & & \\
\hline Age, years & $19.9 \pm 0.7$ & $19.9 \pm 0.7$ & $19.9 \pm 0.8$ & 0.44 \\
\hline Height, cm & $178.3 \pm 7.0$ & $177.5 \pm 5.9$ & $178.0 \pm 6.4$ & 0.46 \\
\hline Weight, kg & $73.4 \pm 12.4$ & $73.0 \pm 13.8$ & $73.3 \pm 12.4$ & 0.92 \\
\hline $\mathrm{BMI}, \mathrm{kg} / \mathrm{cm} 2$ & $23.1 \pm 3.7$ & $23.1 \pm 4.1$ & $23.1 \pm 3.7$ & 0.98 \\
\hline WOMAC overall§̧ & $0.2 \pm 0.5$ & $0.1 \pm 0.3$ & $0.1 \pm 0.4$ & 0.22 \\
\hline WOMAC pain§ & $0.2 \pm 0.7$ & $0.1 \pm 0.4$ & $0.1 \pm 0.5$ & 0.14 \\
\hline WOMAC stiffness & $0.6 \pm 1.6$ & $0.5 \pm 1.4$ & $0.5 \pm 1.3$ & 0.22 \\
\hline WOMAC function $\S$ & $0.1 \pm 0.4$ & $0.1 \pm 0.3$ & $0.1 \pm 0.4$ & 0.51 \\
\hline EuroQol Health State Index§§ & $9.3 \pm 1.3$ & $9.2 \pm 1.3$ & $9.3 \pm 1.3$ & 0.51 \\
\hline EuroQol VAS & $8.5 \pm 1.2$ & $8.2 \pm 1.6$ & $8.5 \pm 1.3$ & 0.02 \\
\hline
\end{tabular}


Table 2: Comparison of measurements in hips with and without cam-type deformity.

347 *For all values the maximum of any plane per patient was used for the analysis, therefore the values may not necessarily add up.

\begin{tabular}{|c|c|c|c|c|}
\hline \multirow[t]{2}{*}{ * } & \multicolumn{2}{|l|}{ Cam-type deformity } & \multirow[b]{2}{*}{ Difference } & \multirow[t]{2}{*}{$p$ value } \\
\hline & $\begin{array}{l}\text { Yes }(n=67) \\
(95 \% \mathrm{Cl})\end{array}$ & $\begin{array}{l}\text { No }(n=177) \\
(95 \% \mathrm{Cl})\end{array}$ & & \\
\hline BP-Angle $\left[{ }^{\circ}\right]$ & $77.44(75.72-79.17)$ & $74.30(73.24-75.36)$ & $3.14(1.12-5.17)$ & 0.002 \\
\hline BC-Angle $\left[{ }^{\circ}\right]$ & $25.92(23.76-28.08)$ & $24.4 \mid(23.07-25.74)$ & $1.51(-1.03-4.06)$ & 0.242 \\
\hline Radius rb bone [mm] & $32.30(31.83-32.77)$ & $31.36(31.07-31.65)$ & $0.95(0.39-1.50)$ & 0.001 \\
\hline Radius rc cartilage [mm] & $27.92(27.44-28.40)$ & $27.94(27.65-28.24)$ & $-0.03(-0.59-0.54)$ & 0.928 \\
\hline Thickness bone [mm] & $3.25(3.02-3.48)$ & $2.59(2.45-2.73)$ & $0.66(0.38-0.93)$ & $<0.000$ \\
\hline Thickness cartilage [mm] & $-1.27(-1.40$ to -1.15$)$ & $-1.40(-1.48$ to -1.33$)$ & $0.13(-0.02-0.27)$ & 0.081 \\
\hline Thickness b \& c [mm] & $3.63(3.39-3.88)$ & $3.03(2.88-3.19)$ & $0.60(0.31-0.89)$ & $<0.000$ \\
\hline Area $[\mathrm{mm} 2]$ & $26.74(24.02-29.45)$ & $21.69(20.02-23.36)$ & $5.05(1.86-8.24)$ & 0.002 \\
\hline
\end{tabular}

350

351

352 Table 3: Comparison of shapes of sclerosis in hips with and without cam-type deformity.

\begin{tabular}{lccrr}
\hline & $\begin{array}{l}\text { With deformity } \\
(n=53 \mathrm{I})\end{array}$ & $\begin{array}{l}\text { Without deformity } \\
(n=1415)\end{array}$ & Odds ratio $(95 \% \mathrm{Cl})$ & $p$ value \\
\hline no visible shape & $10.4 \%$ & $20.0 \%$ & 1 (reference) & - \\
Shape 0 & $0.6 \%$ & $0.7 \%$ & $1.75(0.45-6.86)$ & 0.420 \\
Shape I & $9.4 \%$ & $9.2 \%$ & $2.25(1.29-3.90)$ & 0.004 \\
Shape 2 & $4.3 \%$ & $5.9 \%$ & $1.60(0.84-3.04)$ & 0.151 \\
Shape 3 & $2.6 \%$ & $2.1 \%$ & $2.73(1.26-5.92)$ & 0.011 \\
Shape 4 & $26.4 \%$ & $16.3 \%$ & $3.56(2.17-5.82)$ & $<0.001$ \\
Shape 5 & $26.9 \%$ & $18.0 \%$ & $3.28(2.01-5.35)$ & $<0.001$ \\
Shape 6 & $19.4 \%$ & $27.8 \%$ & $1.53(0.93-2.51)$ & 0.091 \\
\hline
\end{tabular}

354

355

356 Table 4: Intra-rater ICC for the different parameters.

\begin{tabular}{lllllll}
\hline Parameter & diameter & BP angle & BC angle & ra & rb & rc \\
\hline ICC (Pearson) & 0.96 & 0.94 & 0.99 & 0.93 & 0.97 & 0.97 \\
\hline
\end{tabular}


Figure 1: Segment with subchondral sclerosis/length (B) represents the border of the osseous

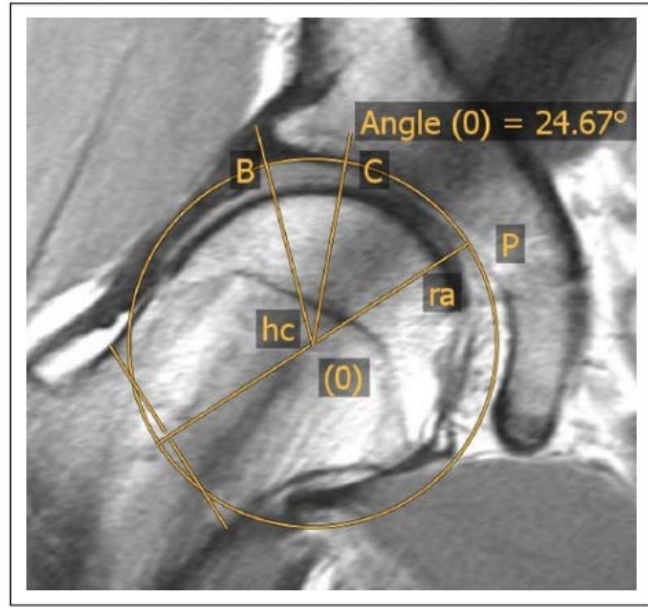

Figure 2: Thickness of the subchondral sclerosis

Example when the sclerosis located at the expense of cartilage and within the bone. The circle with

radius ra is placed on the subchondral bone. From there the circle is shrunk until it reaches the

beginning of the sclerosis in the subchondral bone, resulting in a circle with radius rc. Then the circle

difference between ra and $\mathrm{rb}$ or/and $\mathrm{rc}$ results in the thickness of the subchondral sclerosis.

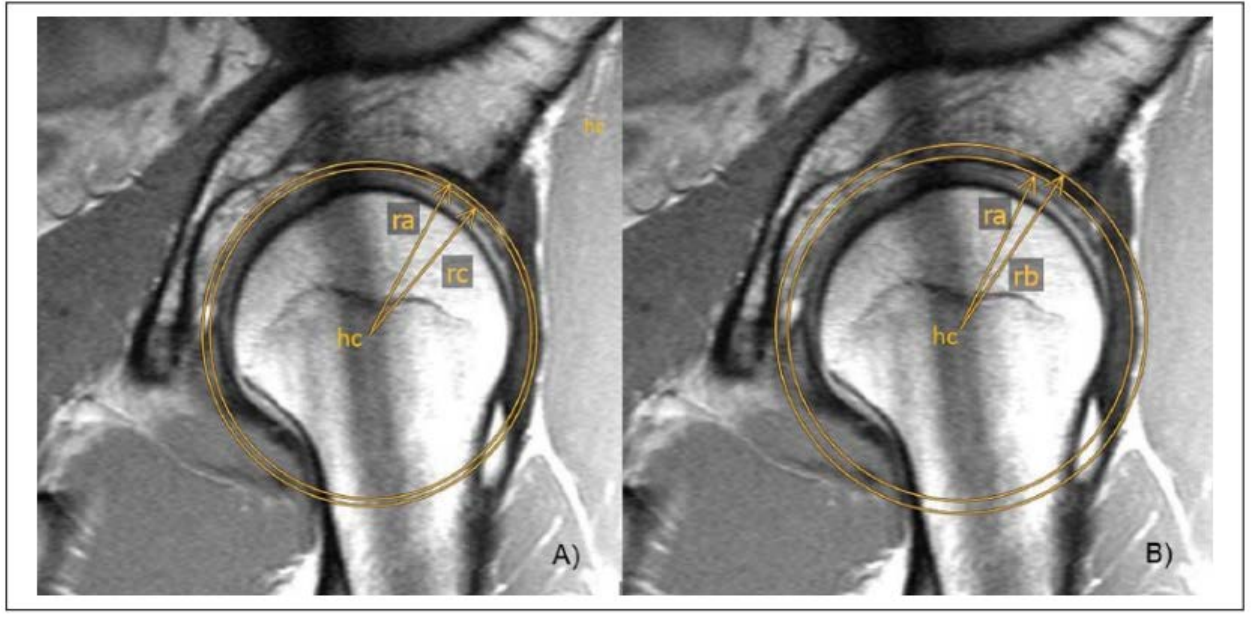


Figure 3: Shape of subchondral sclerosis.

373 (A) Boomerang: 2 wings are divided from the angle near the labrum (B) linear/homogeneous: the

374 hypertrophy shows over the whole length / the same thickness (C) lenticular: the shape of the

375 sclerosis an ellipse (D) hook-shaped: an external part of the sclerosis protrudes or even overhangs

376 toward the surface of the cartilage $(E)$ triangular: the sclerosis has the shape of a triangle $(F)$

377 irregular: the shape of the sclerosis cannot be classified into 1 of the described shapes A-E or $G(G)$

378 semicircular: the shape of the sclerosis semicircular.
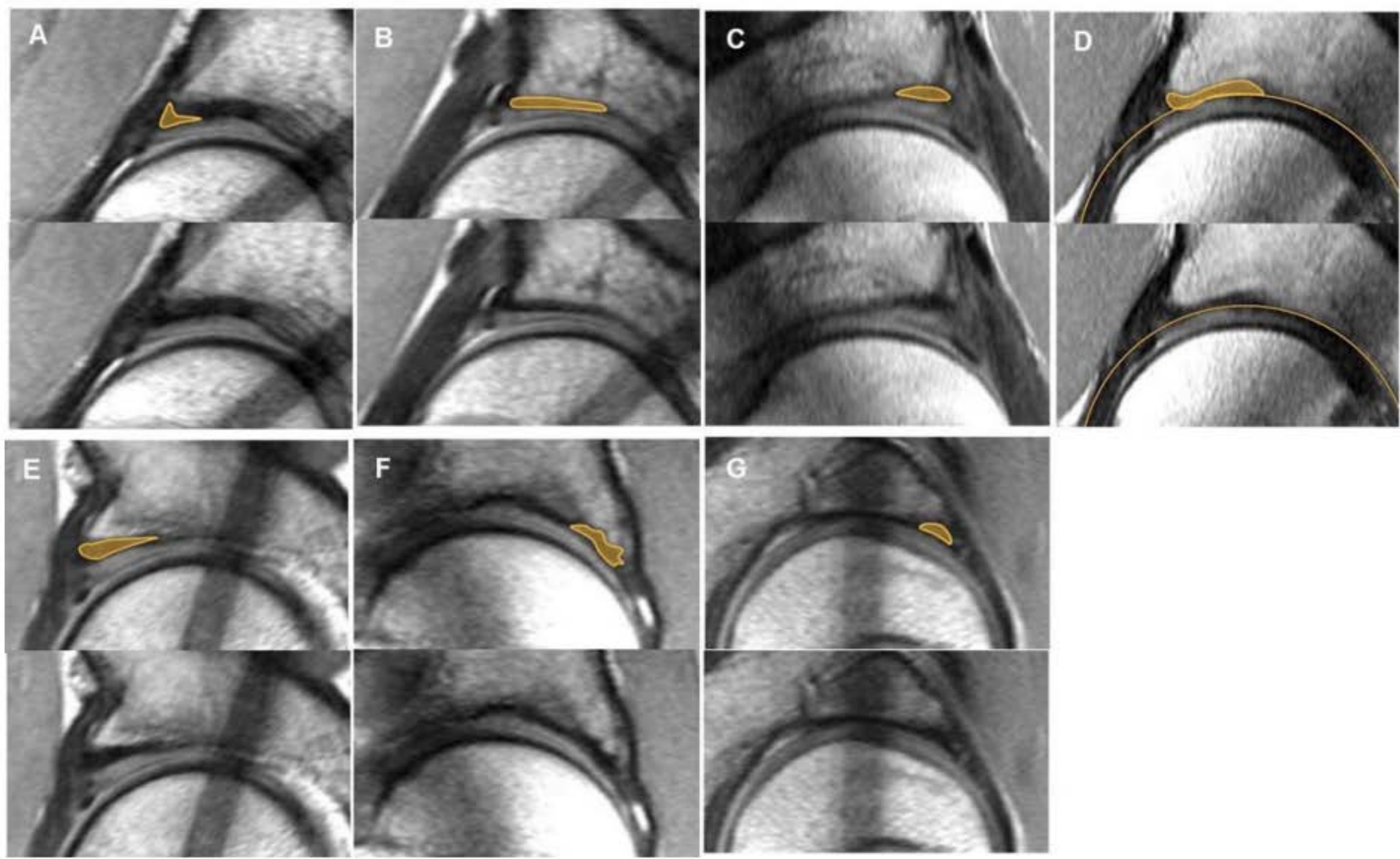

37 . 
381 Figure 4: Study flow chart. Adapted from Reichenbach et al. ${ }^{10}$

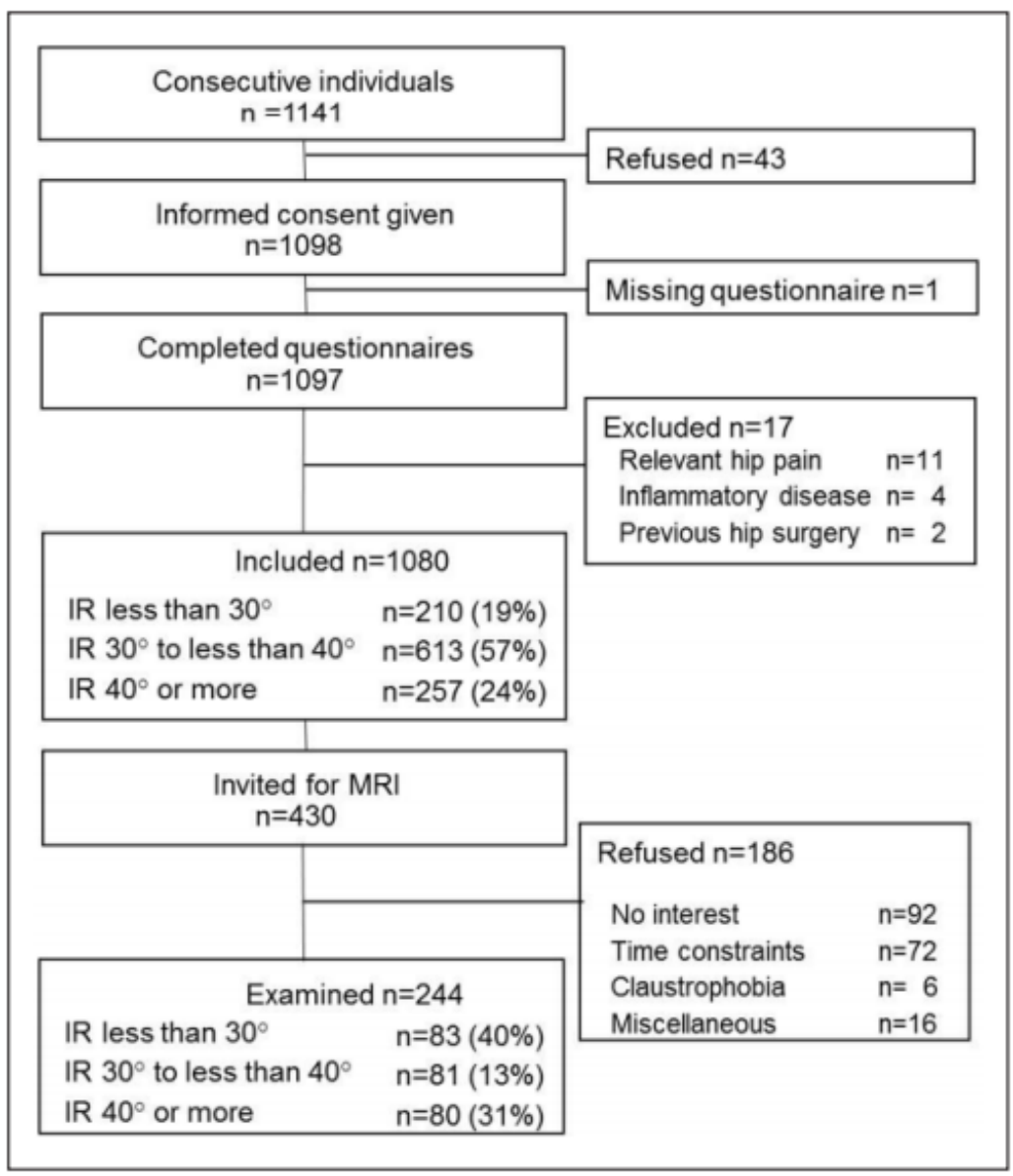

